\title{
Correction to: Perceptions of Support in Chinese Mothers of a Child with Intellectual Disability
}

\author{
Hui Su ${ }^{1,2} \cdot$ Monica Cuskelly ${ }^{2} \cdot$ Linda Gilmore ${ }^{3} \cdot$ Karen Sullivan $^{2}$
}

Published online: 9 August 2021

(c) Springer Science+Business Media, LLC, part of Springer Nature 2021

\section{Correction to: J Dev Phys Disabil (2018) 30:509-525 https://doi.org/10.1007/s10882-018-9599-8}

In the original published version of this article the Funding Information was not captured. Thus, the authors wish to add this information 'National Office for Education Sciences Planning in China (Project Title: Parenting and support for families of children with disabilities from an ecological perspective, Project Number: CHA170264)'.

This erratum is presented to fix the error.

The original article has been corrected.

Publisher's Note Springer Nature remains neutral with regard to jurisdictional claims in published maps and institutional affiliations.

The original article can be found online at https://doi.org/10.1007/s10882-018-9599-8.

Hui Su

hui.su@mail.ccnu.edu.cn

1 Faculty of Education, Central China Normal University, 152 Luoyu RoadHubei Province, Wuhan 430079, China

2 Faculty of Education, Queensland University of Technology, Victoria Park Road, Kelvin Grove, QLD 4059, Australia

3 Faculty of Education, University of Tasmania, TAS, Locked Bag 1307, Launceston 7250, Australia 